\title{
Efficacy of Moringa oleifera leaf powder as a hand- washing product: a crossover controlled study among healthy volunteers
}

\author{
Belen Torondel ${ }^{{ }^{*} \dagger}$, David Opare ${ }^{1 \dagger}$, Bjorn Brandberg ${ }^{2}$, Emma Cobb $^{1}$ and Sandy Cairncross ${ }^{1}$
}

\begin{abstract}
Background: Moringa oleifera is a plant found in many tropical and subtropical countries. Many different uses and properties have been attributed to this plant, mainly as a nutritional supplement and as a water purifier. Its antibacterial activity against different pathogens has been described in different in vitro settings. However the potential effect of this plant leaf as a hand washing product has never been studied. The aim of this study is to test the efficacy of this product using an in vivo design with healthy volunteers.

Methods: The hands of fifteen volunteers were artificially contaminated with Escherichia coli. Moringa oleifera leaf powder was tested as a hand washing product and was compared with reference non-medicated liquid soap using a cross over design following an adaptation of the European Committee for Standardization protocol (EN 1499). In a second part of tests, the efficacy of the established amount of Moringa oleifera leaf powder was compared with an inert powder using the same protocol.
\end{abstract}

Results: Application of 2 and $3 \mathrm{~g}$ of dried Moringa oleifera leaf powder (mean $\log _{10}$-reduction: $2.44 \pm 0.41$ and $2.58 \pm$ 0.34 , respectively) was significantly less effective than the reference soap ( $3.00 \pm 0.27$ and $2.99 \pm 0.26$, respectively; $\mathrm{p}<0.001$ ). Application of the same amounts of Moringa oleifera ( 2 and $3 \mathrm{~g}$ ) but using a wet preparation, was also significantly less effective than reference soap ( $p<0.003$ and $p<0.02$, respectively). However there was no significant difference when using $4 \mathrm{~g}$ of Moringa oleifera powder in dried or wet preparation (mean $\log _{10}$-reduction: $2.70 \pm 0.27$ and $2.91 \pm 0.11$, respectively) compared with reference soap ( $2.97 \pm 0.28$ ). Application of calcium sulphate inert powder was significantly less effective than the $4 \mathrm{~g}$ of Moringa oleifera powder $(p<0.01)$.

Conclusion: Four grams of Moringa oleifera powder in dried and wet application had the same effect as non-medicated soap when used for hand washing. Efficacious and available hand washing products could be useful in developing countries in controlling pathogenic organisms that are transmitted through contaminated hands.

Keywords: Moringa oleifera, Hand-washing product, Antibacterial, Diarrhoea, Tropical countries

\section{Background}

Diarrhoeal diseases are a common cause of morbidity and the leading cause of death among children under five, accounting for $19 \%$ of mortality in this age group [1]. Most of all diarrhoeal deaths of children under five years are in Africa and South East Asia [2]. The vast majority of diarrheal diseases are caused by bacteria, viruses and protozoa,

\footnotetext{
* Correspondence: belen.torondel@lshtm.ac.uk

${ }^{\dagger}$ Equal contributors

'Department of Disease Control, Faculty of Infectious and Tropical Diseases, London School of Hygiene and Tropical Medicine, Keppel Street, London WC1E 7HT, UK

Full list of author information is available at the end of the article
}

mainly found in human faeces which are spread from the stool of one person to the mouth of another. Hands can act as a vector for transmission of faecal pathogens, either via direct person-to-person transmission or by contaminating food that is later consumed [3]. Hand washing after defecation and before handling food is therefore a biologically plausible mechanism for interrupting pathogen transmission. Hands are also transmission vectors for respiratory infections, and interventions promoting hand hygiene have been shown to reduce gastrointestinal and respiratory illnesses by an average of $31 \%$ and $21 \%$, respectively $[4]$.

\section{Biomed Central}


Moringa oleifera is a plant that can grow to 5-10 meters in a year and it is cultivated in many countries from South Asia to West and East Africa [5] (Figure 1). While it grows best in dry, sandy soil, it tolerates poor soil, including coastal areas. It is a fast-growing, drought-resistant tree that is native to the southern foothills of the Himalayas in northwestern India. Over the past two decades, many reports have appeared in mainstream scientific journals describing the nutritional and medicinal properties of Moringa oleifera, including treatment for malaria and intestinal worms, antifungal properties, malnutrition and also as a water purifier [6-10].

Moringa oleifera has been described to have antibacterial activity against some human bacterial pathogens, Gramnegative: Shigella shinga, Pseudomonas aeruginosa, Shigella sonnei, and Pseudomonas spp. and also Gram-positive: Staphylococcus aureus, Bacillus cereus, Streptococcus Bhaemolytica, Bacillus subtilis, Sarcina lutea and Bacillus megaterium [11]. This effect has been attributed to different parts of the plant, such as the leaves, flowers, seeds, roots, fruit peel and unripe pods [5].

There is anecdotal evidence supporting the effect of this plant as an antibacterial agent and its use as a hand washing product [11-13]. However, there are no in vivo studies demonstrating the efficacy of Moringa oleifera leaf powder as a hand-washing product. The aim of this study is to test the efficacy of this product in vivo with healthy volunteers under laboratory controlled conditions.

\section{Methods}

\section{Micro-organism}

In order to test the efficacy of Moringa oleifera leaf powder, we used an adapted protocol of the European Committee for Standardization (EN 1499) [14] which is designed to evaluate the ability of hand-wash agents to eliminate transient pathogens form volunteers' hands without regard to resident micro-organisms. This procedure is based on the

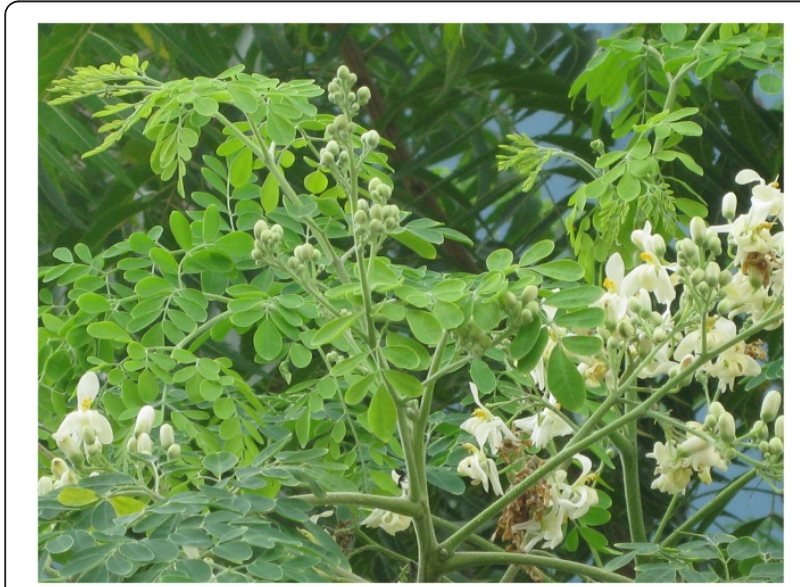

Figure 1 Moringa oleifera tree leaf. "post-contamination treatment" of hands, and involves the placement of the test organism (Escherichia coli (ACTC 25922)) on the hands of test subjects followed by exposure to the test formulation. These methods are useful in testing the performance of products used in routine hand hygiene in health care centres.

\section{Subjects}

The study was performed in the Medical Microbiology Laboratory of the London School of Hygiene and Tropical Medicine (LSHTM) from June to July 2012, and was approved by LSHTM Ethics Committee on 19th April 2012.

Fifteen adult volunteers from LSHTM were selected for the study, and a formal written consent was received from all of them. The volunteers were physically examined to ensure they were healthy with healthy skin. None had skin disorders like eczema, paronychia, scabies, abrasions, lacerations or skin allergy. They all had short fingernails with no artificial nails. They had no history of drug allergy and had not taken any systemic antibiotic in the two weeks prior to the study, which could otherwise impair the efficacy of the product being tested. All forms of jewellery were removed from their hands prior to hand washing, since it had the potential of retaining some bacteria, which could affect the recovery pre and post values.

\section{Moringa oleifeira preparations}

Moringa oleifera leaf powder (100\% natural) was obtained from LUTOR Ltd. (UK). The aim of this study was to test the efficacy of the leaves as a hand washing product in dried and wet preparation and also to test the effect of using different amounts (2, 3 and $4 \mathrm{~g}$ ).

Because we wanted to test more than one preparation, we used a cross-over design with 5 groups of 3 subjects each. For day one, all the three volunteers in the first group used $5 \mathrm{ml}$ of non-medicated liquid soap, $2 \mathrm{~g}$ of dry and wet Moringa oleifera powder as a hand washing product. The other four groups of volunteers repeated the same procedure on days 2, 3, 4 and 5.

During the second and third experiments (which were carried out the same day for each group), the aforementioned procedure was repeated with increasing amounts of Moringa oleifera powder; 3 and 4 g respectively. However, the quantity of non -medicated liquid soap was maintained at $5 \mathrm{ml}$. At the end of the whole series of runs every subject had used each hand-washing product once (Table 1).

\section{Contamination procedure}

The hands of each volunteer were washed with a nonmedicated soap, dried and immersed for 5 seconds in a contamination fluid which contained non-pathogenic Escherichia coli (ACTC 25922) $8.3 \times 10^{8} \mathrm{cfu} / \mathrm{ml}$. Excess of fluid was drained off and hands were air-dried for $3 \mathrm{~min}$. 
Table 1 In vivo study: cross-over arrangement of the Moringa oleifera treatments and non-medicated soap control

\begin{tabular}{|c|c|c|c|c|c|c|}
\hline & & Day 1 & Day 2 & Day 3 & Day 4 & Day 5 \\
\hline & $2 \mathrm{~g}$ wet Moringa & & & & & \\
\hline \multirow[t]{3}{*}{ Experiment $1(n=15)$} & $2 \mathrm{~g}$ dry Moringa & Group $1(n=3)$ & Group $2(n=3)$ & Group $3(n=3)$ & Group $4(n=3)$ & Group $5(n=3)$ \\
\hline & Soap* & & & & & \\
\hline & $3 \mathrm{~g}$ wet Moringa & & & & & \\
\hline \multirow[t]{3}{*}{ Experiment $2(n=15)$} & $3 \mathrm{~g}$ dry Moringa & Group $1(n=3)$ & Group $2(n=3)$ & Group $3(n=3)$ & Group $4(n=3)$ & Group $5(n=3)$ \\
\hline & Soap* & & & & & \\
\hline & $4 \mathrm{~g}$ wet Moringa & & & & & \\
\hline \multirow[t]{2}{*}{ Experiment $3(n=15)$} & $4 \mathrm{~g}$ dry Moringa & Group $1(n=3)$ & Group $2(n=3)$ & Group $3(n=3)$ & Group $4(n=3)$ & Group $5(n=3)$ \\
\hline & Soap* & & & & & \\
\hline
\end{tabular}

*non medicated soap $(5 \mathrm{ml})$.

\section{Pre value}

Bacteria were recovered for the initial pre value by kneading the fingertips of each hand separately for 60 seconds in $10 \mathrm{ml}$ of tryptone soya broth (TSB) without neutralizers. The pre values were estimated using the Miles et al. technique [15].

\section{Hygienic hand washing procedure}

The hands of two thirds of the volunteers were treated with the Moringa oleifera for one minute; the hands of the other third were washed with the reference solution (5 $\mathrm{ml}$ of non-medicated liquid soap) for one minute. Hands treated with dried Moringa oleifera received one of the 3 different amounts (2, 3 or $4 \mathrm{~g}$ ) whilst hands treated with wet Moringa oleifera received 2, 3 or $4 \mathrm{~g}$ of the herb powder plus $20 \mathrm{ml}$ of tap water which was added on the top of the Moringa powder deposited previously into each pair of hands. In both cases the participants then rubbed their hands with the product for 1 minute. Hands were rinsed under running water for 15 seconds and were allowed to dry for 3 minutes.

\section{Post values}

After drying of the hands, the thumbs and fingers of both left and right hands were rubbed in separate petri dishes containing $10 \mathrm{ml}$ of TSB for 60 seconds. Post values were determined using the method of Miles et al. [15]. After the procedure, the volunteers were given medicated soap to wash their hands before going home.

In order to test whether Moringa oleifera powder efficacy could be caused by mechanical friction with the hands, we compared the efficacy of $4 \mathrm{~g}$ of Moringa oleifera powder with an inert dried powder (calcium sulphate powder). The same protocol described before was used.

\section{Statistical analysis}

For both reference and test products, log counts from the left and right hands of each subject were averaged separately, for both pre and post values. The arithmetic means of all individual $\log _{10}$ reduction values were calculated. Statistical analysis was performed with the Statistical Package STATA version 11.0. First it was checked whether the data were normally distributed using Kurtosis and Skewness test. Since the data did not follow a normal distribution, the Wilcoxon matched-pair signed ranks test was used to test for differences between each Moringa oleifera preparation and the reference soap and also between Moringa oleifera and the inert powder. The new product (Moringa oleifera) was considered to have the same efficacy as the reference product (soap) if the mean $\log 10$ reduction factor was not significantly smaller for the former than for the latter. Because of the confirmative nature of the test on this application, the level of significance is set at $p=0.1$. The test is to be used one-sided. The discrimination efficiency of the test procedure described has been set to detect a difference between the two mean $\log$ reduction factors of approximately $0.6 \log$ at a power of $95 \%$.

\section{Results}

Application of 2 and $3 \mathrm{~g}$ of dried Moringa oleifera leaf powder resulted in a mean $\log _{10}$-reduction of $2.44 \pm 0.41$ and $2.58 \pm 0.34$, respectively. The reduction observed was significantly less effective than with the reference soap $(3.00 \pm 0.27$ and $2.99 \pm 0.26$, respectively; $\mathrm{p}<0.001)$ (Table 2). Application of the same amounts of Moringa oleifera ( 2 and $3 \mathrm{~g}$ ) but using a wet preparation was also significantly less effective than reference soap $(\mathrm{p}<0.003$ and $\mathrm{p}<0.02$, respectively). However, when using 4 grams of Moringa oleifera powder in dried or wet preparation there was no significant difference (mean $\log _{10}$-reduction: $2.70 \pm 0.27$ and $2.91 \pm 0.11$, respectively) compared with reference soap $(2.97 \pm 0.28, \mathrm{p}>0.5)$.

When we compared the efficacy of 2, 3 and $4 \mathrm{~g}$ of dried vs. wet Moringa oleifera, our results showed that Moringa oleifera was more efficacious in reducing bacterial contamination when used in wet preparation in all 
Table 2 Mean log reduction factor of $E$. coli after volunteers washing with Moringa oleifera product or reference product (non-medicated liquid soap)

\begin{tabular}{|c|c|c|c|c|}
\hline Product & Mean log reduction factor of Moringa product (SD) & Mean log reduction factor of reference soap (SD) & Difference & $\mathbf{p}$ \\
\hline \multicolumn{5}{|c|}{ Moringa $2 \mathrm{~g}$} \\
\hline Dry & $2.44(0.41)$ & $3.00(0.27)$ & 0.56 & $p=0.00001$ \\
\hline Wet & $2.70(0.31)$ & $3.00(0.27)$ & 0.30 & $p=0.003$ \\
\hline \multicolumn{5}{|c|}{ Moringa $3 \mathrm{~g}$} \\
\hline Dry & $2.58(0.34)$ & $2.99(0.26)$ & 0.41 & $p=0.0001$ \\
\hline Wet & $2.84(0.32)$ & $2.99(0.26)$ & 0.15 & $p=0.03$ \\
\hline \multicolumn{5}{|c|}{ Moringa $4 \mathrm{~g}$} \\
\hline Dry & $2.70(0.27)$ & $2.97(0.28)$ & $0.27^{*}$ & $p=0.06$ \\
\hline Wet & $2.91(0.11)$ & $2.97(0.28)$ & 0.07 & $p=0.16$ \\
\hline
\end{tabular}

$P$ values were derived using Wilcoxon's matched pairs signed-rank tests.

*significantly difference between dry and wet preparations $(p=0.01)$.

the 3 doses, but the difference was significant $\left(0.21 \log _{10}\right.$ higher for the wet than the dried preparation; $\mathrm{p}=0.01$ ) only when $4 \mathrm{~g}$ of Moringa oleifera was used (Table 2). We also observed higher effect when we increased the dose of Moringa oleifera in both wet and dried preparations (Figure 2). The mean $\log _{10}$-reduction with $4 \mathrm{~g}$ of dried Moringa oleifera was significantly greater than with 2 and $3 \mathrm{~g}$ dried preparation $(\mathrm{p}<0.01) .4 \mathrm{~g}$ of wet Moringa oleifera was more efficacious than 2 and $3 \mathrm{~g}$ of wet preparation but the reduction was only significantly higher when compared with $2 \mathrm{~g}$ of wet Moringa oleifera $\left(0.21 \log _{10}\right.$ reduction $(\mathrm{p}=0.01)$.

We wanted to test whether the Moringa oleifera bacterial reduction effect was due to the mechanical friction of hands rubbed when using dried powder. Therefore we selected calcium sulphate as an inert and sterile powder and compared its efficacy with $4 \mathrm{~g}$ of Moringa oleifera in dried and wet preparation. The results are shown in Table 3. Application of $4 \mathrm{~g}$ of dried calcium sulphate resulted in a mean $\log _{10}$-reduction of $2.33 \pm 0.35$ less than those obtained with $4 \mathrm{~g}$ of dried and wet Moringa oleifera $(2.70 \pm 0.27$ and $2.91 \pm 0.11$, respectively, $\mathrm{p}<0.01)$. The reduction observed was also significantly less than with the reference soap; $\mathrm{p}<0.001$ ).

\section{Discussion}

The main finding of this study is that Moringa oleifera can reduce bacterial load on artificially contaminated hands when used as a dried or wet powder formulation. A dose of $4 \mathrm{~g}$ of Moringa oleifera in wet or dried formulation presented the same efficacy as non-medicated soap.

Different studies have shown an in vitro antibacterial effect from Moringa oleifera against different bacteria. Peixoto et al. [16] evaluated the antibacterial effect of aqueous and ethanolic Moringa oleifera leaf extracts on the growth of gram-positive and negative bacteria, and they found that some strains of E. coli, P. aeruginosa and $S$. Enteritidis were resistant to all the Moringa oleifera preparations but the same extracts were most effective



Figure 2 Mean $\log _{10}$ reduction factor of $E$. coli after volunteers washed their hands with different doses of Moringa oleifera and using dried and wet preparations. Amount of reference soap applied was always $5 \mathrm{ml}$. 
Table 3 Mean $\log _{10}$ reduction factor of E.coli after volunteers washing with $\mathbf{4} \mathbf{g}$ of Moringa oleifera product, reference product (non-medicated liquid soap) or inert powder (calcium sulphate)

\begin{tabular}{lllll}
\hline Product & $\begin{array}{l}\text { Mean log reduction factor } \\
\text { of Moringa or ref soap (SD) }\end{array}$ & $\begin{array}{l}\text { Mean log reduction factor } \\
\text { of inert product (SD) }\end{array}$ & Difference & P \\
\hline Moringa 4 g dry & $2.70(0.27)$ & $2.33(0.35)$ & 0.37 & $\mathrm{p}=0.02$ \\
Moringa 4 g wet & $2.91(0.11)$ & $2.33(0.35)$ & 0.58 & $\mathrm{p}=0.0001$ \\
Reference soap & $2.97(0.28)$ & $2.33(0.35)$ & 0.64 & $\mathrm{p}=0.000002$ \\
\hline
\end{tabular}

against S.aureus, V. parahaemolyticus, E. faecalis and A. caviae. Other authors found that aqueous and ethanolic Moringa oleifera leaf extracts were effective against Salmonella [10]. The authors attributed the antibacterial effect to the presence of saponins, tannic, phenolic and alkaloid phytoconstituents [16]. Moringa oleifera leaves had been found in other studies to present an important amount of saponins $(80 \mathrm{~g} / \mathrm{kg})$ [17]. Saponins are chemical compounds which have detergent or surfactant properties [18] and this may explain the bacterial reduction when using Moringa oleifera as a hand washing product.

In this study we also showed a dose-response reduction effect of Moringa oleifera, with a dose of $4 \mathrm{~g}$ associated with a greater bacterial reduction, comparable with the efficacy of non-medicated soap. These results suggest that when using Moringa oleifera, the hands have to be completely full of the powder in order to have the best results. The use of a wet preparation also presented better results than when dried powder was used. This could be explained by the water's effect [19] in extracting more of the active component of the plant at the moment of hand cleansing. Water is a universal solvent, and other many studies have described its ability to extract plant products with antimicrobial activity [19]. Thus the solvents most commonly used for preliminary investigations of antimicrobial activity in plants are methanol, ethanol and water [20-22].

Different studies have found that mechanical friction applied during hand washing plays a role in removing microorganisms adhering to hands [23]. Therefore we tested whether the effect of Moringa oleifera leaf powder could be due only to the mechanical friction exerted when rubbing the hands together. For this purpose we compared the effect of $4 \mathrm{~g}$ of Moringa oleifera leaf powder with inert calcium sulphate powder, and observed that although calcium sulphate could reduce bacterial load on hands, the reduction was significantly smaller than obtained using $4 \mathrm{~g}$ of Moringa oleifera or non-medicated soap. These results suggest that Moringa oleifera has an extra effect due to its active components that cannot be attributed only to the mechanical action of rubbing hands together.

Many regulatory agencies require hand-wash (except for non-medicated soap) and hand-rub agents used in health care settings to meet certain performance standards when assessed using standardized test protocols $[24,25]$. In Europe, the most commonly used laboratory based in vivo methods to test antiseptics are those of the European Committee for Standardization (CEN) [26,27]. EN 1499 [14] and EN 1500 [28] belong to the category of CEN tests designed to evaluate the ability (of handwash or hand-rub agents, respectively) to eliminate transient pathogens from health care workers' hands. This study followed an adaptation of protocol EN1499 which is designed to test the antimicrobial activity of hand wash agents. According to EN 1449, the mean reduction caused by the test product in the number of viable bacteria has to be significantly higher than that obtained with the reference soap [14]. $4 \mathrm{~g}$ of dried or wet Moringa oleifera did not pass this criterion, but it met the EN1500 requirement for a hand-rubbing agent, which said that the mean reduction in the numbers of viable bacteria shall not be significantly inferior to that with the reference product [28]. It can be argued that this product could also meet other standards used in different parts of the world. For example, in USA and Canada such formulations are regulated by the Food and Drug Administration (FDA) and Health Canada, respectively which refer to the standards of ASTM International [29]. Thus, a formulation may meet one criterion, but not another [30]. For example, in a study by Kramer et al. [30], various alcohol-based hand-rub gels accepted by ASTM standards failed to pass the European standards. At present, it remains unknown which requirement is the right one or what reduction in microbial release is needed to produce a meaningful reduction in the hand-borne spread of pathogens [31,32]. In this study we have demonstrated that $4 \mathrm{~g}$ of Moringa oleifera powder has the same effect as non-medicated soap, as both can significantly reduce bacteria counts in artificially contaminated hands. However we suggest this product is more suitable for domestic settings, rather than healthcare settings, where other products have already been demonstrated to be effective and available, and where the use of this powder would be less convenient.

The challenges of using this product in a domestic setting should be explored. How would users accept using a dried plant to clean their hands? How could the 
material be made available in specific domestic points where hand hygiene takes place? One possibility would be to place baskets with dried Moringa oleifera powder and spoons to dispense it, close to crucial places for hand hygiene, for example next to the cooking place and the latrine.

In this study we have demonstrated the effect of dried Moringa oleifera leaves in reducing bacteria on hands. It would be very interesting to test the bacterial reduction effect of fresh leaves. The possibility of using fresh leaves could facilitate its use as preparation process would not be necessary, opening up new avenues for its use, for example in open defecation places where Moringa trees are available.

\section{Conclusion}

Four grams of Moringa oleifera powder in dried and wet application had the same effect as non-medicated soap when used for hand washing. Moringa oleifera could be very useful in places where soap or water is not available, and where this tree grows naturally. It could also be a cheap and healthy hand-washing optional product. Our data have been obtained in a laboratory setting, so the next step will be to try this product in real conditions and study its acceptability and convenience for potential users. Moringa oleifera formulations should be investigated further in randomized controlled trials.

\section{Competing interests}

The authors declare that they have no competing interests.

\section{Authors' contributions}

Idea for the research question: SC, BB, BT. Design of the experiments: BT, DO. Performed the experiments: DO. Analyzed the data: BT, DO. Contributed reagents/materials/techniques: EC. Wrote the paper: BT. Comments and review of paper: SC, DO, EC. All authors' read and approved the final manuscript.

\section{Acknowledgement}

We would like to acknowledge the help of Peter Donachie and his advice in the laboratory work. We also would like to thank Parimita Routray for providing the photo of the Moringa oleifera plant.

This research was funded in part by UK aid from the Department of International Development (DFID) as part of the SHARE research programme (www.SHAREresearch.org). However, the views expressed do not necessarily reflect the Department's official policies.

\section{Author details}

'Department of Disease Control, Faculty of Infectious and Tropical Diseases, London School of Hygiene and Tropical Medicine, Keppel Street, London WC1E 7HT, UK. ${ }^{2}$ SBI Consulting Lda, Av V Lenine 3092-1E, Maputo, Mozambique.

Received: 28 August 2013 Accepted: 20 January 2014

Published: 14 February 2014

\section{References}

1. Black RE, Cousens S, Johnson HL, Lawn JE, Rudan I, Bassani DG, Jha P, Campbell H, Walker CF, Cibulskis R, et al: Global, regional, and national causes of child mortality in 2008: a systematic analysis. Lancet 2010, 375(9730):1969-1987.
2. Boschi-Pinto C, Velebit L, Shibuya K: Estimating child mortality due to diarrhoea in developing countries. Bull World Health Organ 2008, 86(9):710-717

3. Curtis V, Cairncross S: Effect of washing hands with soap on diarrhoea risk in the community: a systematic review. Lancet Infect Dis 2003, 3(5):275-281.

4. Aiello AE, Coulborn RM, Perez V, Larson EL: Effect of hand hygiene on infectious disease risk in the community setting: a meta-analysis. Am J Public Health 2008, 98(8):1372-1381.

5. Anwar F, Latif S, Ashraf M, Gilani AH: Moringa oleifera: a food plant with multiple medicinal uses. Phytother Res 2007, 21(1):17-25.

6. Thilza I, Sanni S, Isah Z, Sanni F, Talle M, Joseph M: In vitro antimicrobial activity of water extract of moringa oleifera leaf stalk on bacteria normally implicated in eye diseases. Acad arena 2010, 2(6):80-82.

7. Ramachandran C, Peter K, Gopalakrishnan P: Drumstick (Moringa oleifera): a multipurpose Indian vegetable. Econ Bot 1980, 34(3):276-283.

8. Chuang P-H, Lee C-W, Chou J-Y, Murugan M, Shieh B-J, Chen H-M: Anti-fungal activity of crude extracts and essential oil of Moringa oleifera Lam. Bioresour Technol 2007, 98(1):232-236.

9. Beltrán-Heredia J, Sánchez-Martín J: Improvement of water treatment pilot plant with Moringa oleifera extract as flocculant agent. Environ Technol 2009, 30(6):525-534.

10. Doughari JH, Pukuma M, De N: Antibacterial effects of Balanites aegyptiaca L. Drel. and Moringa oleifera Lam. on Salmonella typhi. Afr J Biotechnol 2007, 6(19):2212-2215.

11. Rahman MM, Sheikh MMI, Sharmin SA, Islam MS, Rahman MA, Rahman MM, Alam M: Antibacterial activity of leaf juice and extracts of Moringa oleifera Lam. against some human pathogenic bacteria. CMU J Nat SCi 2009, 8(2):219

12. Chopra RN: Glossary of Indian medicinal plants. New Delhi: Council of Scientific \& Industrial Research; 1956.

13. Luqman S, Srivastava S, Kumar R, Maurya AK, Chanda D: Experimental assessment of Moringa oleifera leaf and fruit for its antistress, antioxidant, and scavenging potential using in vitro and in vivo assays. Evid Based Complement Alternat Med 2012, 2012 Article(ID 519084):12.

14. EN1499: Chemical desinfectants and antiseptics. Hygienic hand wash. Test method and requierments. Brussels: Comite Europeen de Normalisation; 1997.

15. Miles A, Misra S, Irwin J: The estimation of the bactericidal power of the blood. J Hyg 1938, 38(06):732-749.

16. Peixoto JRO, Silva GC, Costa RA, Vieira GHF, Vieira RHSF: In vitro antibacterial effect of aqueous and ethanolic Moringa leaf extracts. Asian Pac J Trop Med 2011, 4(3):201-204.

17. Ferreira PMP, Farias DF, Oliveira JTA, Carvalho AFU: Moringa oleifera: bioactive compounds and nutritional potential. Rev Nutr 2008, 21(4):431-437.

18. Sharma V, Paliwal R: Isolation and characterization of saponins from Moringa oleifera (moringaceae) pods. Int J Pharm Pharm Sci 2013, 5(1):179-183.

19. Das K, Tiwari R, Shrivastava D: Techniques for evaluation of medicinal plant products as antimicrobial agent: current methods and future trends. J of Med plants Res 2010, 4(2):104-111.

20. Parekh J, Jadeja D, Chanda S: Efficacy of aqueous and methanol extracts of some medicinal plants for potential antibacterial activity. Turk J Biol 2005, 29:203-210

21. Lourens A, Reddy D, Başer K, Viljoen A, Van Vuuren S: In vitro biological activity and essential oil composition of four indigenous South African Helichrysum species. J Ethnopharmacol 2004, 95(2):253-258.

22. Rojas JJ, Ochoa VJ, Ocampo SA, Muñoz JF: Screening for antimicrobial activity of ten medicinal plants used in colombian folkloric medicine: a possible alternative in the treatment of non-nosocomial infections. BMC Complement Altern Med 2006, 6(1):2.

23. Kampf G, Kramer A: Epidemiologic background of hand hygiene and evaluation of the most important agents for scrubs and rubs. Clin Microbiol Rev 2004, 17(4):863-893.

24. Boyce JM, Pittet D: Guideline for hand hygiene in health-care settings: recommendations of the Healthcare Infection Control Practices Advisory Committee and the HICPAC/SHEA/APIC/IDSA Hand Hygiene Task Force. Infect Control Hosp Epidemiol 2002, 23(S12):S3-S40.

25. World Health Organization: Guidelines for hand hygiene in health care. Geneva: World Health Organization; 2009.

26. Austrian Society for Hygiene, Microbiology and Preventive Medicine (OEGHMP): Guideline of the OEGHMP as of November 4th, 1980, for 
testing the efficacy of procedures for hygienic hand disinfection. Oesterr Krankenhausz 1981, 22:23-31. in German.

27. German Society for Hygiene and Microbiology: Guidelines for testing and rating of chemical disinfectants. Zentralbl Bakteriol Hyg I Abt Orig B 1981, 172:528-556. in German

28. EN1500: Chemical desinfectants and antiseptics. Hygienic hand wash. Test method and requirements. Brussels: Comite Europeen de Normalisation; 1997.

29. United States Food and Drug Administration: Tentative Final Monograph for healthcare antiseptic drug products; proposed rule. Fed Regist 1994, 3:31441-31452.

30. Kramer A, Rudolph P, Kampf G, Pittet D: Limited efficacy of alcohol-based hand gels. Lancet 2002, 359(9316):1489-1490.

31. Rotter ML: Hand washing and hand desinfection, Mayhall CG, editor Hospital epidemiology and infection control. Philadelphia, PA: Lippincott, Williams\&Wilkins; 2004.

32. Larson EL: APIC guideline for handwashing and hand antisepsis in health care settings. Am J Infect Control 1995, 23(4):251.

doi:10.1186/1472-6882-14-57

Cite this article as: Torondel et al: Efficacy of Moringa oleifera leaf powder as a hand- washing product: a crossover controlled study among healthy volunteers. BMC Complementary and Alternative Medicine 2014 14:57

\section{Submit your next manuscript to BioMed Central and take full advantage of:}

- Convenient online submission

- Thorough peer review

- No space constraints or color figure charges

- Immediate publication on acceptance

- Inclusion in PubMed, CAS, Scopus and Google Scholar

- Research which is freely available for redistribution 